\title{
PROGNOSIS AFTER RESECTION OF SMALL BOWEL IN THE NEWBORN*
}

\author{
BY \\ VALENTINE A. J. SWAIN, ALEXANDER PEONIDES and WINIFRED F. YOUNG
From the Queen Elizabeth Hospital for Children, London
}

This report concerns the results in a series of children who have had a resection of small bowel for obstruction in the neonatal period. The recovery rate after this procedure has improved, particularly at special centres, but the presence of multiple abnormalities such as cardiovascular disorders and prematurity increases the risk of operation. The first few days of the post-operative period are often hazardous after complete obstruction from atresia (single or multiple), due largely to disparity in the size of the anastomosed bowel above and below the obstruction. The distended and hypertrophied proximal gut, sometimes containing viscid meconium, contrasts with the collapsed distal bowel which never having functioned is small in diameter. The excision of dilated bowel above the obstruction, advocated by Gross (1953), Nixon (1955) and others, has helped the recovery of such cases, but where the whole of the proximal gut is distended in high jejunal obstruction, its excision is often not possible, and recovery of intestinal function may be greatly delayed.

Massive resections may be necessary in volvulus intestinalis neonatorum or mesenteric vascular thrombosis. Animal experiments (Flint, 1912) and studies after massive resections in adults (Haymond, 1935) indicate that at least half of the intestine can be removed with recovery. Preservation of the ileum is more important than the jejunum for absorption in general (Kremen, Linner and Nelson, 1954; Benson, 1955), and absorption of vitamin $B_{12}$ in particular (Booth and Mollin, 1957; 1959) is dependent on the distal small bowel. After resection of a moderate length of bowel, dysfunction with intestinal hurry may persist for several weeks, but ultimately the bowel functions normally (Booth, Evans, Menzies and Street, 1959). This recovery may be due to compensatory hypertrophy of intestinal villi, as shown in animal experiments (Flint,

\footnotetext{
* A paper read at a meeting of the British Association of Paediatric Surgeons in London, September 1962.
}

1912). Kremen et al. (1954) have shown that preservation of the ileocaecal valve is essential in preventing severe intestinal hurry in animals that have lost most of their ileum. Where stagnation of the bowel contents occurs following enteroanastomosis, malabsorption, anaemia and other features of the 'blind loop' syndrome may be expected, due to vitamin and mineral deficiencies. The anaemia is usually of macrocytic and hyperchromic type. This alimentary dysfunction is attributed to abnormal growth of bacteria within the stagnant loop, extending to the proximal small intestine. It has been produced experimentally in animals (Badenoch, 1958; Card, 1959). After resection of the intestine, therefore, the outcome depends not only on the amount and type of bowel remaining, but also on the function of the stoma at the site of the anastomosis. Short-circuiting by-pass procedure should be avoided and the risk of a stenotic junction lessened by modifications of technique, such as the use of single layer junction with interrupted absorbable sutures.

Small intestinal sequelae are often difficult to diagnose, but straight abdominal radiographs, and pictures taken after giving an opaque medium where indicated, may detect a persistent dilated loop of bowel. Conservative treatment with modification of diet and antibiotics is worth trying, but if it fails excision of the offending loop may be necessary.

In summary, babies who have had a short length of bowel resected can be expected to recover and develop well, whereas large resections may lead to malnutrition from malabsorption. This may show itself by retarded growth, signs of mineral and vitamin deficiencies or, if the lower ileum is missing, by specific defects such as macrocytic anaemia. Both at the beginning and at follow-up examinations, co-operation between the paediatric surgeon and physician is clearly essential in treating these cases, in order to detect alimentary sequelae and constitutional disturbances and so avoid retarded development whenever possible. 


\section{Present Study}

Between 1953 and 196042 newborn babies were admitted to the Queen Elizabeth Hospital with small bowel obstruction; 18 patients required resection of the small bowel and the present study concerns only these. At the time of operation 16 were aged between 1 and 6 days; the other two were 12 and 28 days, the obstruction being complete in all except the last. Diagnosis of intestinal obstruction rested upon the clinical findings supported by the radiological appearances of the abdomen on a straight film taken erect. Before operation each patient was given an intravenous infusion to correct deficits of water and electrolytes from vomiting, from pooling of fluid in the gut proximal to the obstruction and from starvation. These infusions were continued to replace deficits during the period of post-operative ileus and to provide maintenance requirements of water, electrolytes and some calories as glucose, until oral feeding could be resumed. The plan for assessing the requirements for such treatment was based on clinical, laboratory and balance data described and discussed elsewhere (Young, McIntosh, Swain and Levin, 1959).

Table 1 shows the site, cause of obstruction and results in this series of 18 patients. Among the 13 infants surviving the post-operative period, three with meconium ileus had cystic fibrosis of the pancreas, and one with a jejuno-ileal septum was a mongol. The birth weight of each exceeded $5 \mathrm{lb}$. $(2 \cdot 26 \mathrm{~kg}$. $)$ which may have contributed to recovery.

Table 2 shows the findings in the five who died during the post-operative period. Two were premature infants weighing less than $4 \mathrm{lb} .(1 \cdot 81 \mathrm{~kg}$.) at birth, one of whom was grossly dehydrated before operation at the age of 6 days, and the other required a massive resection. One of the others who weighed less than $5 \mathrm{lb}$. $(2 \cdot 26 \mathrm{~kg}$.) at birth also had persistent ileus. In the remaining two obstruction was due to inspissated meconium which was not amenable to surgical treatment.

\section{Progress}

Table 3 is a summary of the course in the 11 infants who survived. Three of those surviving the post-operative period underwent a second operation for closure of an ileostomy and two to overcome the initial obstruction, one of which then had the ileostomy closed at a third operation. One had a Ramstedt operation for hypertrophic pyloric stenosis at an older age, and another developed intestinal obstruction due to adhesions, at the age of 11 weeks, which was relieved by a further operation.
Two of those suffering from cystic fibrosis of the pancreas, who were making good early progress, succumbed to pulmonary complications, one at 6 weeks and the other at 4 months of age. Each had had resection of about $50 \mathrm{~cm}$. of ileum, and the first had had a Ramstedt operation for pyloric stenosis.

Since it can be supposed that full recovery of alimentary function depends upon the extent of a resection, the course of four patients from whom $45-67 \mathrm{~cm}$. of small gut were removed has been compared with that of seven who lost $5-30 \mathrm{~cm}$. Recovery in seven was uneventful, but in four (three of the first and one of the second group) it was complicated early after the operation. One had diarrhoea from intestinal hurry, and three had complications due to dilatation of a loop proximal to the site of anastomosis. All failed to thrive, three became anaemic and A.D., the patient with intestinal hurry, became dehydrated from gross electrolyte depletion. He had had excision of the longest piece of the bowel in this series. J.B., with alimentary dysfunction following a long resection, had, and probably still has, recurring partial obstruction in the region of the anastomosis, but the dilatation of bowel in two others (J.L., J.C.) only persisted for two or three months. L.D., with good early progress, developed alimentary symptoms and anaemia years later. At 6 years of age a 'blind loop syndrome' was diagnosed and the loop resected with recovery of normal bowel function thereafter. These five cases are described in detail.

\section{Present Review}

Of the 11 surviving patients, nine, whose ages range from 3 to 8 years, have been re-examined for alimentary sequelae and nutritional state. Each has been examined also for anaemia, hypoproteinaemia, rickets and retardation of skeletal age and for steatorrhoea by analysis of a three-day collection of stools, except in the patient with cystic fibrosis of the pancreas.

Fig. 1 shows that, except for J.B.'s height and A.W.'s weight (each of which is above the 3rd percentile), both the height and the weight of each child are above the 10th percentile, and above the 50th percentile in five children. The skeletal age of all except A.W. is also within the normal range. None of the children has anaemia, hypoproteinaemia or rickets, but J.B. and L.D. who have a recent history of malabsorption had been given iron during a preceding period.

The fat excretion has been estimated in four of the five children who had had complications and in 
TABLE 1

SITE AND CAUSE OF SMALL BOWEL OBSTRUCTION IN 18 NEWBORNS

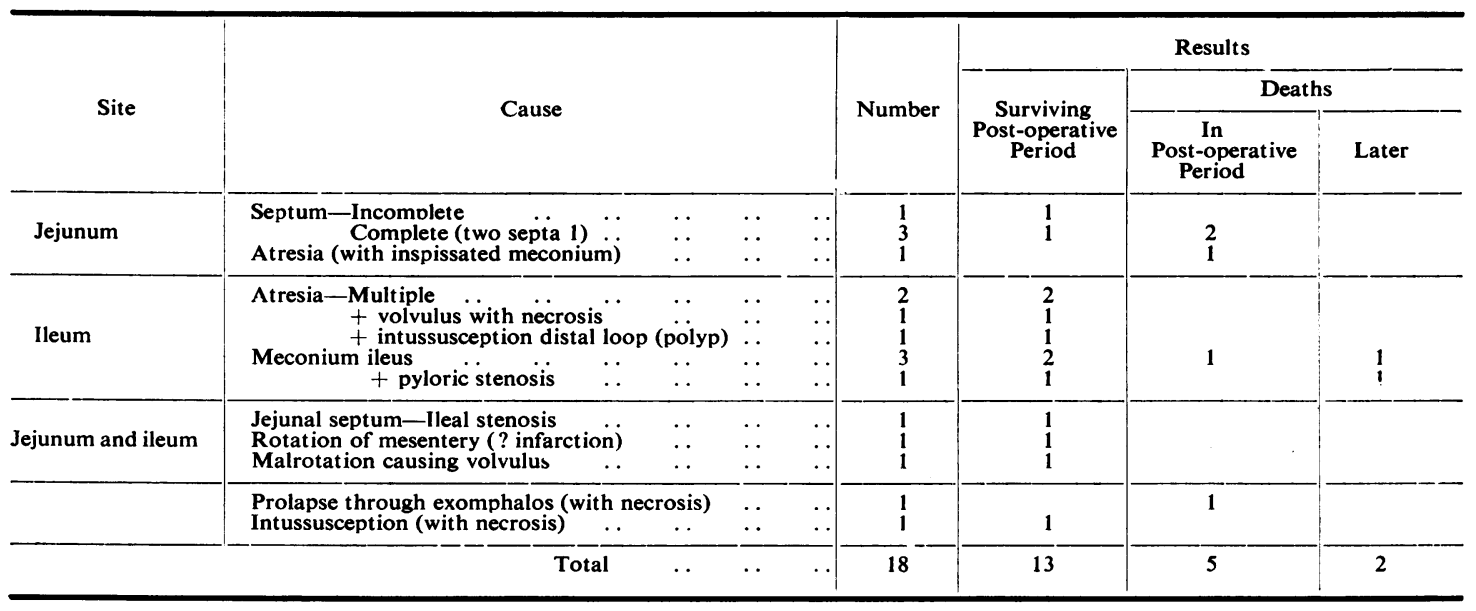

TABLE 2

FINDINGS IN PATIENTS WHO DIED DURING POST-OPERATIVE PERIOD

\begin{tabular}{|c|c|c|c|c|c|c|c|}
\hline \multirow{2}{*}{\multicolumn{2}{|c|}{$\begin{array}{l}\text { Birth } \\
\text { Weight }\end{array}$}} & \multirow{2}{*}{$\begin{array}{l}\text { Age at } \\
\text { First } \\
\text { Operation } \\
\text { (days) }\end{array}$} & \multicolumn{2}{|r|}{ Obstruction } & \multirow{2}{*}{$\begin{array}{c}\text { Total } \\
\text { Length of } \\
\text { Small Bowel } \\
\text { Resected } \\
\text { (cm.) }\end{array}$} & \multirow{2}{*}{ Condition After Operation } & \multirow{2}{*}{$\begin{array}{l}\text { Age at } \\
\text { Death } \\
\text { (days) }\end{array}$} \\
\hline & & & Site & Cause & & & \\
\hline 4 & 8 & 5 & Jejunum & One septum & 7 & Ileus persisted after $t$ wo operations & 20 \\
\hline 3 & 11 & 6 & Jejunum & Two septa & 16 & $\begin{array}{l}\text { Electrolyte imbalance after gross } \\
\text { dehydration }\end{array}$ & 8 \\
\hline 4 & 13 & 2 & Jejunum & $\begin{array}{l}\text { Atresia }+ \text { inspissated meco- } \\
\text { nium } \\
\text { Cystic fibrosis of pancreas }\end{array}$ & 20 & $\begin{array}{l}\text { Unrelieved obstruction (two opera- } \\
\text { tions) }\end{array}$ & 7 \\
\hline 7 & 6 & 2 & Ileum & $\begin{array}{l}\text { Meconium ileus } \\
\text { Cystic fibrosis of pancreas }\end{array}$ & 65 & $\begin{array}{l}\text { Unrelieved obstruction (two opera- } \\
\text { tions) until high ileostomy at } \\
17 \text { days }\end{array}$ & 35 \\
\hline 3 & 3 & 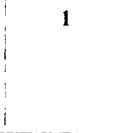 & Ileum and colon & $\begin{array}{l}\text { Prolapse through exomphalos } \\
\text { (with necrosis) }\end{array}$ & $\begin{array}{c}45 \\
(+ \text { caecum } \\
+8 \mathrm{~cm} . \text { of } \\
\text { descending } \\
\text { colon) }\end{array}$ & Poor; ileus persisted & 6 \\
\hline
\end{tabular}

FIG. 1.-The lines graphed as 10 th and 90 th percentiles represent the average for both boys and girls (Tanner, 1958). The weights of the two patients (B.M. and J.L.) when last recorded at 6 months and 8 months of age lay on the 3rd and 50th percentile respectively.

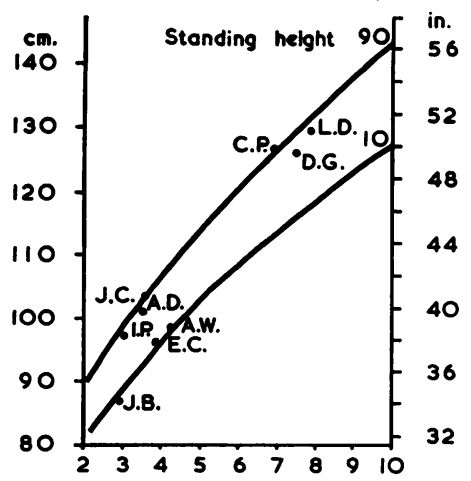

Age in years 
TABLE 3

FINDINGS AND COURSE OF 11 SURVIVING PATIENTS

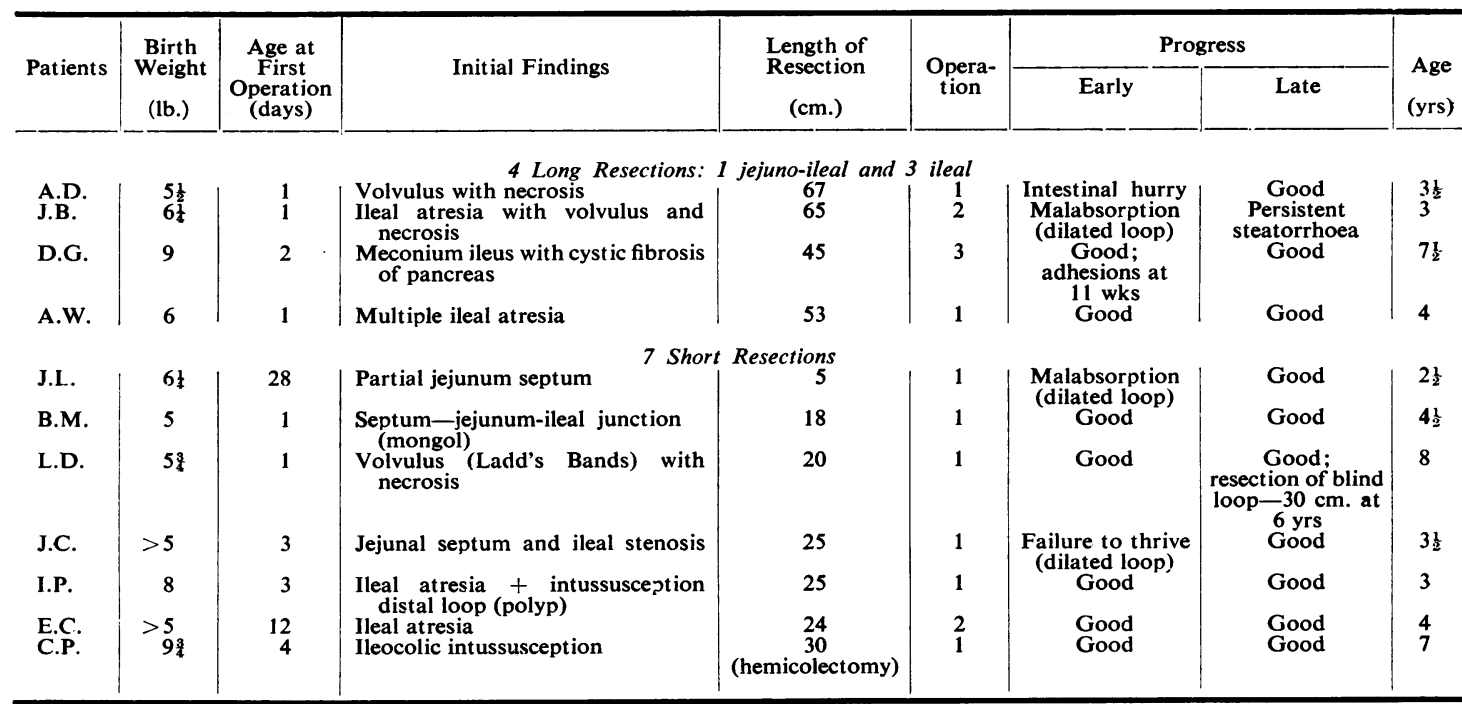

four of the six who had not. The results (Table 4) show that only J.B. has persistent steatorrhoea. L.D.'s fat output was normal for the first time one year after resection of the blind loop.

\section{Case Reports}

Case 1. A.D. This infant had intestinal hurry after a long resection of small gut. He had melaena, oedema of the abdominal wall and a palpable mass in the right iliac fossa on the day after birth. At operation, rotation of the mesentery was found to have caused gangrene (? infarction) of the small intestine. $67 \mathrm{~cm}$. of jejunum and ileum were resected and an end-to-end anastomosis made.

Fig. 2 illustrates the management of the malabsorption phase. Expressed breast milk was introduced as soon as bowel function had been restored, but the baby failed to thrive and at 3 weeks was $\frac{1}{2} \mathrm{lb}$. $(0 \cdot 22 \mathrm{~kg}$.) below his

TABLE 4

STOOL OUTPUT IN EIGHT CHILDREN AT PRESENT REVIEW

\begin{tabular}{c|c|c}
\hline Number & Progress & \multicolumn{1}{|c}{$\begin{array}{c}\text { Stool Output } \\
\text { (Average for 3 Days) }\end{array}$} \\
\hline 4 & Uncomplicated & Normal \\
2 & Complicated early only & $\begin{array}{c}\text { Normal; slightly increased } \\
\text { bulk, no steatorrhoea }\end{array}$ \\
$\begin{array}{c}\text { (A.D.) } \\
\text { (J.C.) }\end{array}$ & $\begin{array}{c}\text { Complicated early and } \\
\text { late; ? persisting dil- } \\
\text { ated loop } \\
\text { (J.B.) }\end{array}$ & $\begin{array}{c}\text { Increased bulk, fluctuating } \\
\text { steatorrhoea, fat/day }= \\
14 \cdot 0 \text { and 4.6 g. } \\
\text { Complicated late only; } \\
\text { well after blind loop } \\
\text { Increased bulk, no steator- } \\
\text { rhoea }\end{array}$ \\
\hline
\end{tabular}

birth weight. Thereafter he began to have diarrhoeal stools and became dehydrated with severe acidosis requiring intravenous administration of alkalis. Expressed breast milk failed to maintain hydration and electrolyte balance during a phase of persistent diarrhoea, and he became emaciated and had severe hypochromic anaemia. Immediate treatment with intravenous infusions was given to restore the deficiencies. Since the chronic diarrhoea was regarded as secondary to the resection, intravenous fluids were followed by an easily assimilable diet, as expressed breast milk supplemented with casein hydrolysate and sodium and potassium salts, the amounts of the salts being increased until they were sufficient to offset the losses.

At 7 weeks the baby began to gain weight and three weeks later a half cream dried milk mixture was substituted gradually and the mineral supplements withdrawn, without relapse. He went home at 11 weeks.

Frequent stools and a tendency to anaemia continued, and there were two further short episodes of diarrhoea, but the child thrived and his weight reached the 3rd percentile at 8 months. Thereafter his stools were normal and he was given a free diet. His weight was nearing the 25th percentile at 1 year and was above the 75 th percentile at 18 months. He was then attempting to walk and physical and mental development were normal.

Reassessment at $3 \frac{1}{2}$ years shows that he is normal in every respect. His I.Q., which was tested because of a speech defect, is 90 .

Case 2. J.B. This infant had malabsorption after a long resection of small gut. Fig. 3 illustrates management of the case.

At operation on the first day of life a blind-ended 

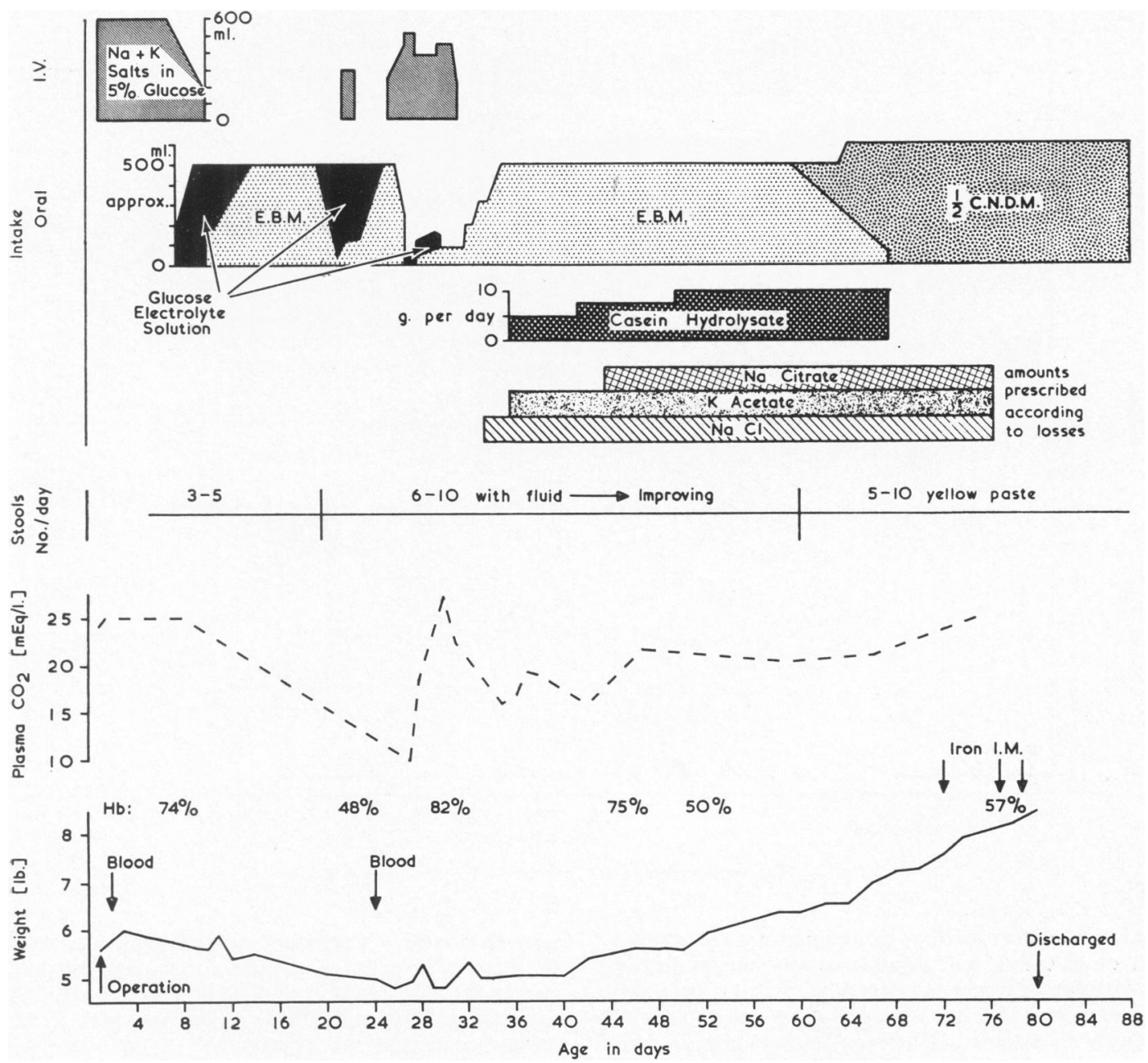

Fig. 2.-The management of A.D. during the first three months of life.

terminal ileum with necrotic volvulus was found. $65 \mathrm{~cm}$. of terminal ileum were resected and an ileostomy made. Intestinal hurry with heavy losses from the ileostomy resulted in electrolyte imbalance despite intravenous fluid therapy. The ileostomy was closed 15 days later and an end-to-end ileocaecal anastomosis made. The post-operative course was complicated by transient cardiac failure, thought to be due to a pulmonary infarct. Later progress seemed satisfactory, although the stools were still frequent and sometimes loose and the weight had not reached the 3rd percentile at discharge from hospital at the age of $2 \frac{1}{2}$ months. Half cream dried milk was given, supplemented with vitamins.

At 5 months of age the baby was readmitted with an acute episode of diarrhoea and vomiting that responded to regrading of the feeds from glucose and electrolyte solutions to milk, and to neomycin orally, but the stools remained loose and $\mathbf{1 0}$ days later there was rectal bleeding associated with anaemia. However, the appetite was good and the baby had gained weight. The feeds were again regraded and blood in the stools was only seen once in hospital. Further episodes of rectal bleeding occurred at $7 \frac{1}{2}$ months and $8 \frac{1}{2}$ months, but the appearance of the bowel was normal at sigmoidoscopy and examination by a barium enema. The child was obviously suffering from progressive malnutrition with hypotonia and severely retarded development. A carmine marker given on three occasions was passed within three to eight hours, showing intestinal hurry. The abdomen was distended and intermittent visible peristalsis was seen; analysis of the stools (Table 5) showed steatorrhoea, and straight radiograph of the abdomen revealed dilatation of the ileum proximal to the anastomosis, but no obstruction. 


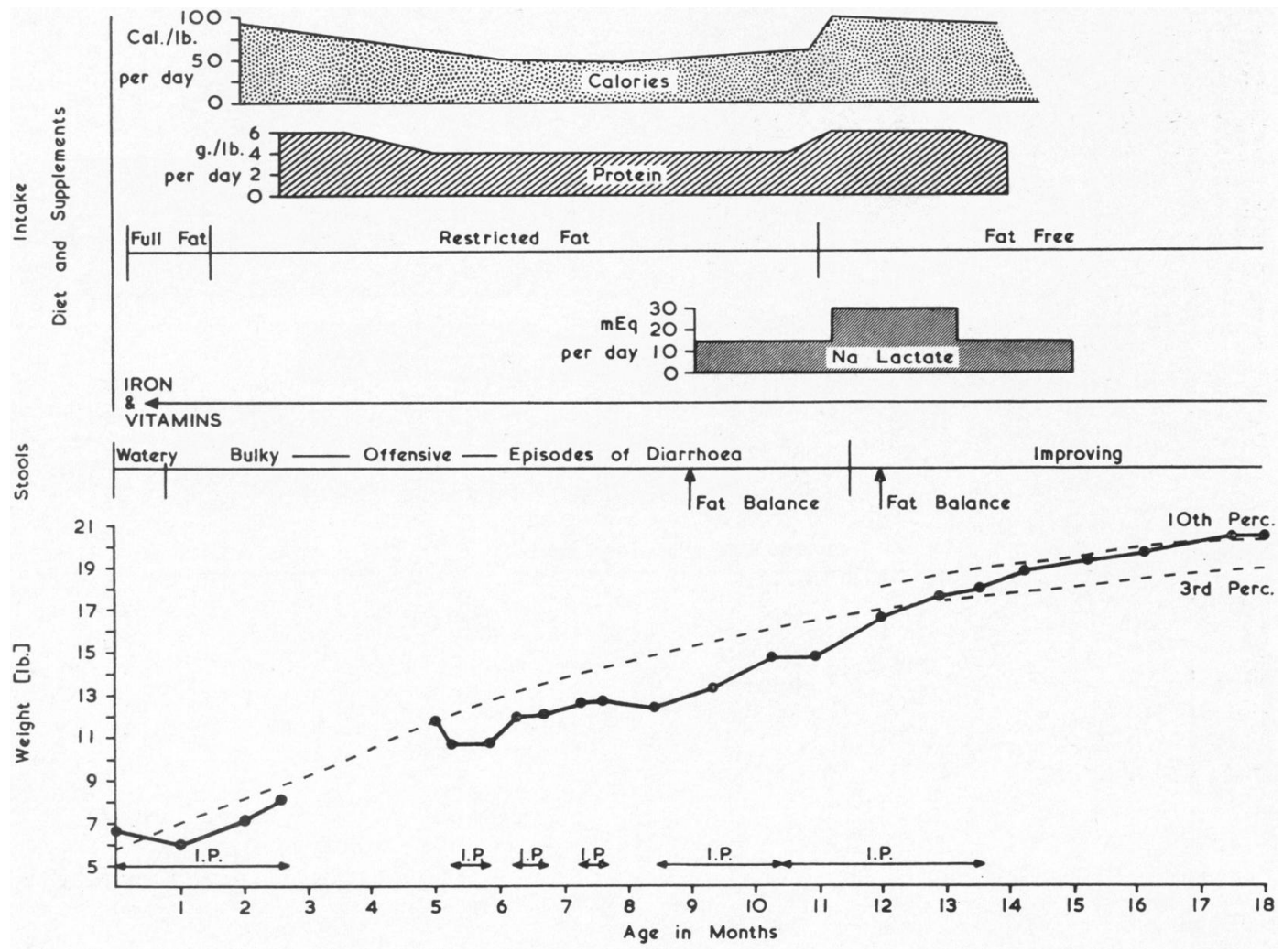

Fig. 3.-The management of J.B. during the first 18 months of life.

It was, therefore, decided to continue medical treatment with a high calorie and protein and very low fat diet with full vitamin and iron supplements. Alkalis, as sodium lactate, were added to offset losses in the stools and a tendency to acidosis. The stool output improved and the child began to gain weight regularly from 11 months, sitting up soon after her first birthday.

At 15 months she was discharged on the same modified diet but no longer requiring such a high caloric intake or salt supplements. Iron supplements were continued until 20 months. The stools were normal in appearance at 19 months and the abdomen was then no longer distended. The child was beginning to walk. Subsequently more fat was introduced and was well tolerated. A stool collection at 2 years and 2 months showed increased bulk but a normal fat output; and there was no recurrence of anaemia after withdrawal of iron. The child had continued to grow and gain weight. Reassessment at 3 years, however, has revealed fluctuating steatorrhoea, but no clinical or haematological

TABLE 5

SERIAL PERIPHERAL BLOOD AND STOOL EXAMINATION IN J.B.

\begin{tabular}{|c|c|c|c|c|c|c|c|c|}
\hline \multirow[b]{2}{*}{$\begin{array}{c}\text { Age } \\
\text { (years) }\end{array}$} & \multicolumn{2}{|c|}{ Blood } & \multirow[b]{2}{*}{$\underset{(\mu \mu \mathrm{g} . / \mathrm{ml} .)}{\text { Serum }} \mathbf{B}_{12}$} & \multirow{2}{*}{$\begin{array}{c}\text { Fat } \\
\text { Intake } \\
\text { (g./day) }\end{array}$} & \multicolumn{2}{|c|}{ Stool Output } & \multirow{2}{*}{$\begin{array}{c}\text { Fat } \\
\text { Absorption } \\
(\%)\end{array}$} & \multirow{2}{*}{$\begin{array}{c}\mathbf{B}_{12} \\
\text { Absorption } \\
(\%)\end{array}$} \\
\hline & $\mathrm{Hb} \%$ & C.I. & & & $\begin{array}{c}\text { Dry Weight } \\
\text { (g./day) }\end{array}$ & $\begin{array}{c}\text { Fat } \\
\text { (g./day) }\end{array}$ & & \\
\hline $\begin{array}{l}1^{3} \\
22^{\frac{2}{2}} \\
2 \frac{1}{12} \\
3^{\frac{1}{2}}\end{array}$ & $\begin{array}{c}72^{*} \\
100^{*} \\
85 \\
81\end{array}$ & $\begin{array}{l}0.73 \\
0.96 \\
0.86 \\
0.85\end{array}$ & $\bar{z}$ & $\begin{array}{c}21 \\
12 \\
\text { Restricted } \\
\text { Restricted } \\
\text { Free }\end{array}$ & $\begin{array}{l}13 \cdot 3 \\
10 \\
38 \\
48 \\
24\end{array}$ & $\begin{array}{r}5.7 \\
1.7 \\
2.1 \\
13.9 \\
4.6\end{array}$ & $\begin{array}{c}72 \cdot 5 \\
83 \cdot 7 \\
= \\
=\end{array}$ & $\begin{array}{l}\overline{\bar{z}} \\
\overline{4} \ddagger\end{array}$ \\
\hline
\end{tabular}

* On oral iron.

$\dagger$ Normal 140-900 $\mu \mu \mathrm{g} . / \mathrm{ml}$.

$\ddagger$ Normal $5 \%$. 


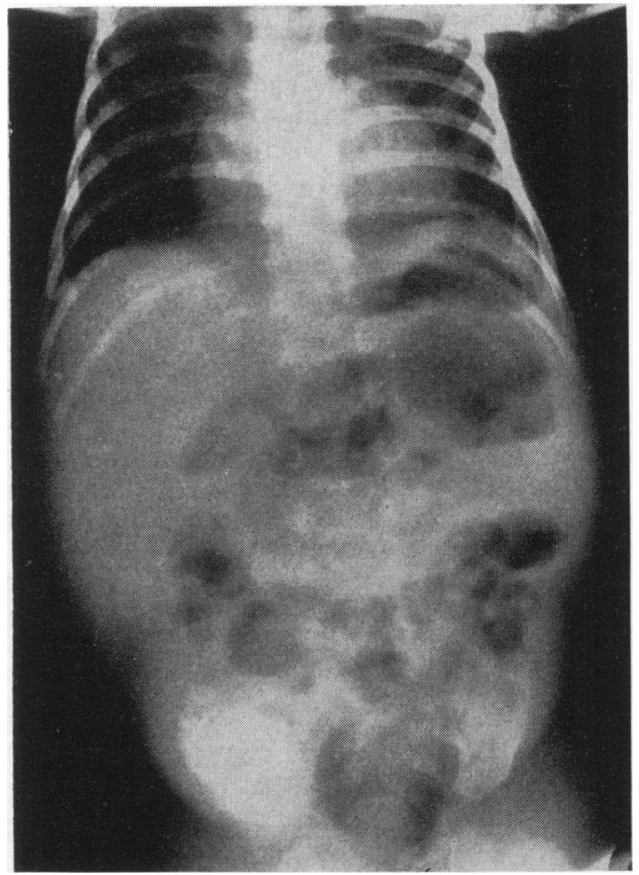

FIG. 4.-Straight radiograph of abdomen erect, showing dilated jejunal loop with fluid level, in J.C. aged 2 months.

deterioration. The appetite is excellent, the patient being reported to eat more than her sister aged 7 years. She is probably compensating for losses in the stools by this high intake.

Cases 3 and 4. J.C. and J.L. These infants had a short resection and temporary failure to thrive associated with dilated jejunal loops.

J.C. At operation on the third day of life a complete jejunal septum and also ileal stenosis were found. $10 \mathrm{~cm}$. of jejunum and $15 \mathrm{~cm}$. of ileum were resected, and an end-to-end jejuno-jejunal and ileo-ileal anastomosis made. Ileus persisted and intravenous fluids were given for 12 days. Oral feeding was then introduced, but the baby vomited and became dehydrated, again requiring intravenous administration of fluids. Subsequently expressed breast milk, later supplemented with casein hydrolysate and salt, was tolerated, but the weight remained below $5 \mathrm{lb}$. $(2 \cdot 26 \mathrm{~kg}$.) until the fifth week. On radiological examination (Fig. 4) a persistently dilated loop of jejunum was found, and the haemoglobin fell to $64 \%$ and serum proteins to $5 \cdot 39 \mathrm{~g}$. $/ 100 \mathrm{ml}$. Thereafter he began to gain weight and tolerated cow's milk mixtures; at the age of 3 months he was $8 \mathrm{lb} .6 \mathrm{oz}$. and was discharged from hospital. Unlike the other infants with sequelae, this baby's stools, although at first curdy, were never bulky and offensive. Apart from occasional vomiting with abdominal fullness in the beginning, he has continued to thrive and is symptom free at $3 \frac{1}{2}$ years.
He is well grown and alimentary absorption is normal, except for some increase in the bulk of the stools.

J.L. Intermittent vomiting delayed diagnosis until 4 weeks of age when obstruction was found to be due to an incomplete septum of the jejunum: $5 \mathrm{~cm}$. were resected and an end-to-end anastomosis made.

Oral feeding with clear fluids was begun two days after operation and subsequently graded to expressed breast milk and a full cream cow's milk mixture, but this was not well tolerated, the baby vomiting and having loose motions with steatorrhoea. Radiological examination revealed a dilated loop of jejunum. Expressed breast milk was given and tolerated, but not half cream cow's milk introduced at 3 weeks of age, for the stools again deteriorated and the child's weight became stationary. After returning to expressed breast milk, now supplemented with casein hydrolysate, the baby thrived, but at 10 weeks a barium meal still showed a dilated loop. The baby weighed $12 \mathrm{lb}$. $\left(5 \cdot 44 \mathrm{~kg}\right.$.) at $4 \frac{1}{2}$ months, and a change to a cow's milk mixture was then well tolerated. Iron supplements were given and the haemoglobin rose from $65-84 \%$. Her weight reached $16 \mathrm{lb} .14 \mathrm{oz}$. (7.6 kg.) at discharge from hospital, aged 7 months, and $18 \mathrm{lb} .4 \frac{1}{2} \mathrm{oz} .(8 \cdot 27 \mathrm{~kg}$.) at 8 months. She is said to be completely well, but has not been available for reassessment.

Case 5. L.D. This girl (older than the other cases) had malabsorption due to a 'blind loop'.

On the second day of life $20 \mathrm{~cm}$. of the upper jejunum had been resected for volvulus and an end to end jejunojejunal anastomosis made, with satisfactory progress after operation, although the viability of areas of the ileum had been doubted (Fig. 5). Malrotation of the intestine was also found at operation. Thereafter the patient remained symptom free and her growth was normal.

At 2 years, bouts of abdominal pain and vomiting occurred. After this she remained well until 4 to 5 years old, when she became tired and listless. A severe hypochromic anaemia ( $\mathrm{Hb} 40 \%-6 \cdot 1 \mathrm{~g} . / 100 \mathrm{ml}$.; colour index 0.66 ) was treated elsewhere with iron given orally and intramuscularly. The stools contained occult blood, but steatorrhoea was not demonstrated. A barium meal showed malrotation of the gut only. Since only the anaemia suggested malabsorption at this time and the child's condition was satisfactory, an operation was not advised.

At 5 years 10 months, while on holiday, the patient was admitted to hospital with signs of subacute intestinal obstruction. This episode was treated medically and recommendations made for investigation on return. In the interval she had recurring bouts of abdominal pain after meals and persistently offensive, bulky stools. At 6 years and 1 month, although the weight and height were both above the 50th percentile, malabsorption was shown by a daily output of fat of $7 \cdot 2 \mathrm{~g}$. On a $40 \mathrm{~g}$. intake (Table 6), and the stools contained occult blood. The haemoglobin was $60 \%$; colour index 0.6 , and the plasma proteins were $5.6 \mathrm{~g} . / 100 \mathrm{ml}$. Jejunal biopsy was normal. 


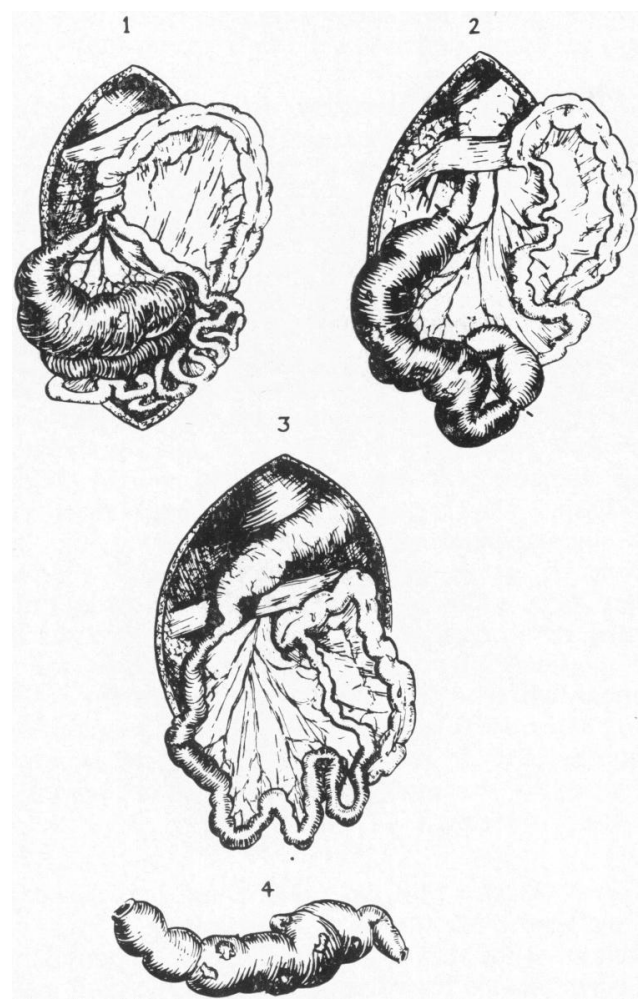

FIG. 5.-Findings at first operation in L.D. The viability of most of the ileum remaining after the resection was doubtful.

1. Volvulus of the entero-colic around the superior mesenteric vessels.

2. After untwisting the volvulus the extrinsic band obstructing the duodenum can be seen.

3. This band is divided and the gangrenous portion of the jejunum is resected.

4. Length of bowel removed.

A barium meal showed malrotation of the caecum and a dilated area of small bowel containing little barium (Fig. 6).

At operation, a dilated U-shaped loop $30 \mathrm{~cm}$. long, with stenosis due to adhesions, $60 \mathrm{~cm}$. above the ileocaecal valve, was resected (Fig. 7), many adhesions and bands divided, and an ileo-ileal anastomosis made. The sac probably developed from a portion of the ileum where the viability was doubted at the first operation.

Recovery after operation was straightforward, but alimentary absorption was still poor five months later, although the child was well. After a further eight months, absorption of fat was normal, with slight increase in the bulk of the stools, but a history of vague abdominal pain, probably related to constipation was obtained. A restricted fat intake (about $40 \mathrm{~g}$. daily) was given in hospital and the patient was symptom free.

Follow-up at 7 years and 10 months, one year and eight months after the second operation, revealed that she was well on a restricted fat intake and had gained $7 \mathrm{lb} .(3 \cdot 17 \mathrm{~kg}$.) and grown 4 in. $(10 \cdot 16 \mathrm{~cm}$.), being on the 70th percentile for weight and height.

At 8 years 4 months on an increased intake of fat of $81 \mathrm{~g}$./day the fat output was $5.6 \mathrm{~g}$./day with some increase in the bulk of the stools.

\section{Discussion}

In adults Haymond (1935) regards removal of at least one-third (more than $200 \mathrm{~cm}$.) of the small bowel as a massive resection, liable to cause sequelae. According to Potts (1955), the average length of the small intestine of the newborn infant is $308 \mathrm{~cm}$., whereas Benson states that it measures $233 \mathrm{~cm}$. in premature and $253 \mathrm{~cm}$. in full-term infants. The loss of $80-100 \mathrm{~cm}$. in an infant is therefore a massive resection by adult standards.

The immediate sequelae to a massive resection in adults and in experimental animals (Jackson, 1958; Pullan, 1959), are due to intestinal hurry, causing profuse diarrhoea. This phase which is likely to continue for some weeks may be fatal unless special care is taken to replace the losses with water and electrolyte solutions given parenterally. The difficulty of maintaining nutrition must be greater in infants where provision for growth has to be made. In a later phase the adult patient may overcome his intestinal disability as long as the diet is suitable,

TABLE 6

SERIAL PERIPHERAL BLOOD AND STOOL EXAMINATION BEFORE AND AFTER OPERATION IN L.D.

\begin{tabular}{|c|c|c|c|c|c|c|c|c|}
\hline \multirow[b]{2}{*}{$\begin{array}{c}\text { Age } \\
\text { (years) }\end{array}$} & \multicolumn{2}{|c|}{ Blood } & \multirow[b]{2}{*}{$\begin{array}{c}\text { Serum B12 } \\
(\mu \mu \mathrm{g} . / \mathrm{ml} .)\end{array}$} & \multirow{2}{*}{$\begin{array}{c}\text { Fat } \\
\text { Intake } \\
\text { (g./day) }\end{array}$} & \multicolumn{2}{|c|}{ Stool Output } & \multirow{2}{*}{$\underset{(\%)}{\text { Fat }} \underset{\substack{\text { Aborption } \\
(\%)}}{ }$} & \multirow{2}{*}{$\underset{(\%)}{\mathbf{B}_{12}}$} \\
\hline & $\mathrm{Hb} \%$ & C.I. & & & $\begin{array}{l}\text { Dry Weight } \\
\text { (g./day) }\end{array}$ & $\underset{\text { (g./day) }}{\text { Fat }}$ & & \\
\hline \multirow{2}{*}{ 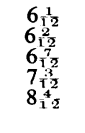 } & 58 & $0 \cdot 6$ & 一 & \multirow{2}{*}{$\begin{array}{c}40 \\
\text { Resection } \\
49 \\
42 \\
81\end{array}$} & \multirow{2}{*}{\begin{tabular}{|c|}
22 \\
blind loop \\
27 \\
$14 \cdot 5$ \\
$26 \cdot 2$
\end{tabular}} & $7 \cdot 2$ & 82 & - \\
\hline & $\begin{array}{r}86 \\
104 \\
98\end{array}$ & $\begin{array}{l}0 \cdot 86 \\
1 \cdot 0 \\
-\end{array}$ & $\bar{z}$ & & & $\begin{array}{l}6 \cdot 1 \\
2 \cdot 6 \\
5 \cdot 6\end{array}$ & $\begin{array}{l}87 \cdot 5 \\
94 \\
93\end{array}$ & $\frac{-}{15 \dagger}$ \\
\hline
\end{tabular}

\footnotetext{
* Normal 140-900 $\mu \mu \mathrm{g} . / \mathrm{ml}$.
}

$\dagger$ Normal $5 \%$. 

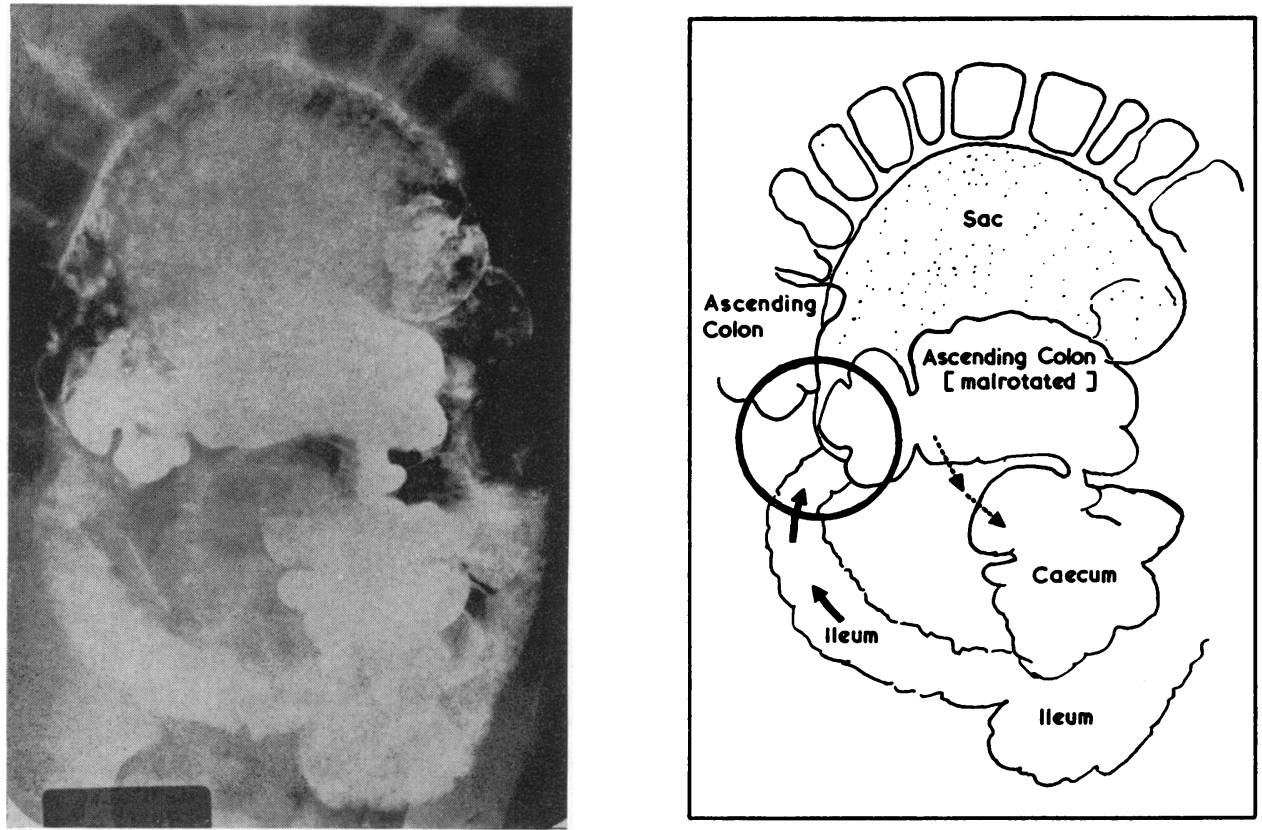

FIG. 6.-The barium follow-through examination in L.D., age 6 years, showing loops of ileum leading to an enormously dilated ileal loop (sac), and malrotation of the caecum and part of the ascending colon. The dilated loop was probably causing obstruction to the ascending colon (circled in the drawing).

Suggested radiological diagnoses were reduplication of the small bowel or a very large Meckel's diverticulum.

but he remains liable to relapses at the slightest stress or following dietary indiscretions.

Few reports of later progress following massive resection in the newborn period are available. Pilling and Cresson (1957) describe two newborns who survived losing all but 26 and $28 \mathrm{~cm}$. of their small intestine, exclusive of the duodenum. Both had intestinal hurry lasting for four to six weeks after operation, but their intestinal function then improved. However, the stools did not become normal until the age of 4 years in one, and in the other were still abnormal at the age of 15 months. Clark and Booth (1960) described gross steatorrhoea and vitamin $B_{12}$ deficiency in an infant after the removal of approximately four-fifths of the distal bowel during the first week. He was successfully treated with vitamin $\mathbf{B}_{12}$ given parenterally, but steatorrhoea persisted.

Potts states that an infant is unlikely to survive after the removal of more than $38 \mathrm{~cm}$. of bowel. Nevertheless, there are four survivors in this series who had longer lengths of bowel resected (Table 2). None of the patients had a massive resection, if this is defined as over $80 \mathrm{~cm}$., but A.D. lost $67 \mathrm{~cm}$. of jejunum and ileum, and J.B. $65 \mathrm{~cm}$. of terminal ileum. A.D. developed severe intestinal hurry

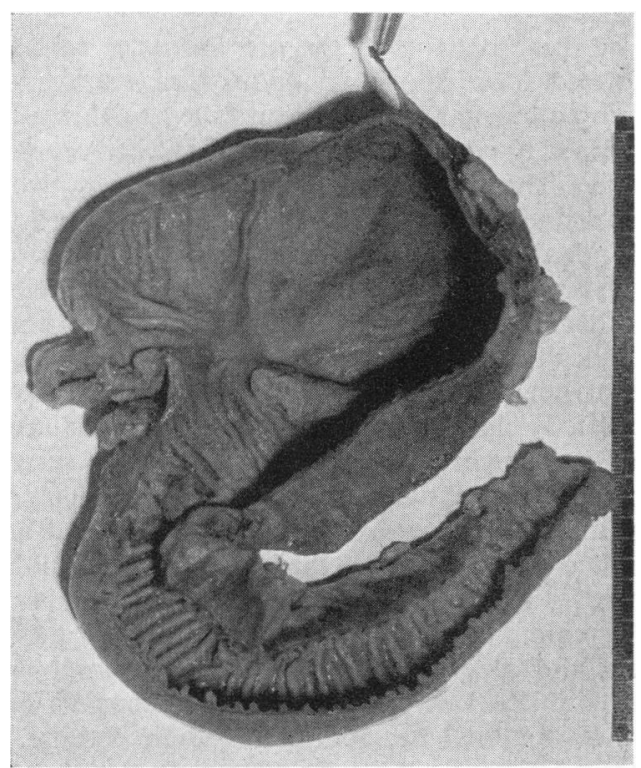

Fig. 7.-The enormously dilated loop of the terminal ileum with moderately dilated proximal loop, resected from L.D., age 6 years, for comparison with the radiographic appearances shown in Fig. 6. 
which lasted for two months and endangered his life at times. Surprisingly he had had no later evidence of chronic malabsorption and tolerated a normal diet from the age of 8 months. On the other hand, J.B. had intestinal hurry after an ileocaecal anastomosis and has continued to suffer from malabsorption, probably due in part to dilatation of the ileum with stasis proximal to the anastomosis. This child has recently needed little dietary restriction and her alimentary function is improving each year and it now seems improbable that surgery will be necessary.

Instances of the 'blind loop' syndrome, with stagnation of intestinal contents leading to malabsorption, following resection of bowel in newborns have been reported by Mason Brown (1952; 1957) in two, Clawson (1953) in one, and Benson (1955) in two cases. Each had had a side-to-side anastomosis of the small intestine, and was successfully treated by excision of the blind loop and restoration of bowel continuity by an end-to-end anastomosis. More recently Benson, Lloyd and Smith (1960) have reported six cases among 28 newborns who survived long enough after their original operation to develop the syndrome. In each case it followed a side-to-side or an end-to-end anastomosis, with or without resection of small bowel. Three improved with conservative treatment after long periods in hospital, two were cured after resection and end-to-end anastomosis, and one died.

The three patients in the present series who had a dilated loop above an end-to-end anastomosis causing alimentary dysfunction failed to thrive and developed hypochromic anaemia in the early months of life. The dysfunction persisted for only two to three months in J.C. and J.L., but steatorrhoea and abdominal distension have persisted with remissions until the age of 3 years in J.B., as already described. Another patient, L.D., who had had no serious complications in the early phase presented with steatorrhoea and anaemia years later, due to a 'blind loop' far below the site of the original anastomosis in a part of the gut that had been severely damaged by obstruction due to volvulus. She resembles adults with the 'blind loop' syndrome, but her anaemia, like that of the three infant patients, was microcytic and hypochromic on examination of the peripheral blood. Serum $\mathrm{B}_{12}$ levels and $\mathrm{B}_{12}$ absorption from the bowel were assayed in the two patients with late sequelae, since Girdwood (1962) has found that these estimations may detect vitamin $B_{12}$ deficiency that is not apparent on peripheral blood examination. J.B. (Table 5) has a low serum $B_{12}$ level of $140 \mu \mu \mathrm{g} . / \mathrm{ml}$. and subnormal $B_{12}$ absorption suggesting that she should be given $B_{12}$ parenterally, but L.D. (Table 6) has findings well within the normal range.

Treatment of alimentary dysfunction due to a dilated loop proximal to the anastomosis has been conservative, using easily assimilable low residue diets, supplied as human milk fortified with simple carbohydrates, casein hydrolysate, vitamins and mineral salts. When this food was tolerated and the infant began to thrive, homogenized meat and vegetables were added, and a low fat cow's milk mixture substituted. In our experience further surgical treatment can be delayed indefinitely and may never be necessary. In contrast, a 'blind loop' causing considerable disability in an older child, such as L.D., obviously requires excision.

\section{Summary}

The course of 18 infants following resection of $5-67 \mathrm{~cm}$. of small intestine for obstruction during the neonatal period is described. Five died during the post-operative period and two from pulmonary infection, associated with cystic fibrosis of the pancreas, later. Eleven survivors have been followed to date.

The course of four was complicated soon after operation, one had intestinal hurry and three malabsorption due to a dilated loop above the anastomosis. Each has been treated conservatively and only one has persistent alimentary dysfunction. This child, J.B., now aged 3 years, has recurrent steatorrhoea, but her nutrition is good and she is symptom free.

One patient without early complications presented at 6 years of age with anaemia and alimentary symptoms from a 'blind loop'. This was resected with improvement.

The alimentary function and nutritional state of nine of the patients, between 3 and 8 years of age, have been reassessed. The findings were normal except in J.B., and in one patient with cystic fibrosis of the pancreas, who remains well on a suitable diet and pancreatin.

The two patients who are not available for reassessment, one of whom is a mongol, were last seen at 6 and 8 months of age and were well.

The long-term prognosis following resection of the small bowel during the neonatal period is good, judged by the results in this series of patients, and no worse after a long than a short resection.

The authors wish to thank their medical colleagues at the Queen Elizabeth Hospital for Children for permission to study and treat the infants admitted under their care; the pathologists, Dr. B. Levin for the biochemical and haematological findings, and Dr. N. France for reports on the specimens of resected bowel and 
autopsy findings; and Dr. C. J. Hodson for the radiological studies. We are also indebted to Mr. L. T. Clifford for the photographs and Mrs. S. Tucker for the diagrams.

The generosity of the British Council, and Messrs. Cow and Gate Ltd., in supporting Dr. A. Peonides by a research grant, is gratefully acknowledged.

\section{REFERENCES}

Badenoch, J. (1958). The blind loop syndrome. In Modern Trends in Gastroenterology, ed. F. Avery Jones, 2nd series, p. 231. Butterworth, London.

Benson, C. D. (1955). Resection and primary anastomosis of the jejunum and ileum in the newborn. Ann. Surg., 142, 478.

, Lloyd, J. R. and Smith, J. D. (1960). Resection and primary anastomosis in the management of stenosis and atresia of the jejunum and ileum. Pediatrics, 26, 265.

Booth, C. C., Evans, K. T., Menzies, T. and Street, D. F. (1959). Intestinal hypertrophy following partial resection of the small bowel in the rat. Brit. J. Surg., 46, 403.

- and Mollin, D. L. (1957). Importance of ileum in the absorption of vitamin $B_{12}$. Lancet, 2, 1007 ibid., 1,18 .

Card, W. I. (1959). 'Blind loop' syndrome. Proc. roy. Soc. Med. $52,28$.

Clark, A. C. L. and Booth, C. C. (1960). Deficiency of vitamin B12 after extensive resection of the distal small intestine in an infant. Arch. Dis. Childh., 35, 595.
Clawson, D. K. (1953). Side to side intestinal anastomosis, complicated by ulceration, dilatation and anemia; a physiologically unsound procedure. Surgery, 34, 254.

Flint, J. M. (1912). The effect of extensive resections of the sma!l intestine. Johns Hopk. Hosp. Bull., 23, 127.

Girdwood, R. H. (1962). Malabsorptive disorders; investigations and their bearing on treatment. In symposium: 'The study of normal and disordered function of the small intestine'. Roy. Coll. Phys. Edin. Pub., 17, 7.

Gross, R. E. (1953). The Surgerv of Infancy and Childhood, 1st ed. Saunders, Philadelphia and London.

Haymond, H. E. (1935). Massive resection of the small intestine; an analysis of 257 collected cases. Surg. Gynec. Obstet., 61, 693.

Jackson, W. P. U. (1958). Massive resection of the small intestine. In Modern Trends in Gastroenterology, ed. F. Avery Jones, 2nd series, p. 243. Butterworth, London.

Kremen, A. J., Linner, J. H. and Nelson, C. H. (1954). An experimental evaluation of the nutritional importance of proximal and distal small intestine. Ann. Surg., 140, 439.

Mason Brown, J. J. (1952). Surgical aspects of vomiting in the newborn. Trans. med.-chir. Soc. Edinb., 51.

(1957). Small intestine obstruction in the newly born. Ann. roy. Coll. Surg. Engl., 20, 280.

Nixon, H. H. (1955). Intestinal obstruction in the newborn. Arch. Dis. Childh., 30, 13.

Pilling, G. P. and Cresson, S. L. (1957). Massive resection of the small intestine in the neonatal period. Pediatrics, 19, 940.

Potts, W. J. (1955). Pediatric surgery. J. Amer. med. Ass., 157, 627. Pullan, J. M. (1959). Massive intestinal resection. Proc. roy. Soc. Med., 52, 31 .

Tanner, J. M. (1958). The evaluation of physical growth and development. In Modern Trends in Paediatrics, ed. A. Holzel and J. P. M. Tizard, 2nd series, p. 325. Butterworth, London.

Young, W. F. McIntosh, J., Swain, V. and Levin, B. (1959) Parenteral fluid therapy for children undergoing major abdominal surgery; a study of 120 consecutive cases. Brit.J. Surg , 47, 261. 